\title{
A territorialização da informação: uma análise do jornalismo nas rádios locais portuguesas
}

\section{Luís Bonixe}

Doutor em Ciências da Comunicação, especialização em Jornalismo, pela Universidade Nova de Lisboa. Professor de Jornalismo no Instituto Politécnico de Portalegre. Investigador na área do jornalismo radiofónico. Membro do Centro de Investigação de Média e Jornalismo e da C3i. Fundador do grupo de investigação em Rádio e Meios Sonoros da Sopcom.

E-mail: luis.bonixe@gmail.com
Resumo: As rádios locais representam uma das principais revoluções no setor das mídias em Portugal após a revolução de 25 de Abril de 1974, que acabou com um regime de ditadura no país. De um cenário caracterizado pela existência de três principais rádios e algumas pequenas emissoras passou-se para quase quatro centenas de emissoras espalhadas pelo país. As rádios locais abriram espaço para a presença das comunidades locais nos meios de comunicação, representando um novo palco para novas vozes e temáticas. No entanto, hoje assitimos a uma crise de identidade que afeta a sua razão de existência. Há rádios locais que são apenas retransmissoras de outras emissoras, algumas encerraram portas e uma parte significativa das que sobrevivem fazem-no com enormes dificuldades. No presente artigo analisamos a partir de vários indicadores a situação das rádios locais em Portugal no início do século XXI.

Palavras-chave: Rádio local; Jornalismo; Portugal.

Title: The territorialization of the news: an analysis of the journalism in Portuguese local radio

Abstract: Local radio represents a major revolution in the media sector in Portugal after the revolution of April 25, 1974, which ended with a dictatorship in the country. A scenario characterized by the existence of three main radio stations and some small stations went up to nearly four hundred stations around all over the country. Local radio represented a space for the presence of local communities in the media, representing a new stage for new voices and themes. However, today we assist to an identity crisis that affects its reason for existence. There are local radios that only relay other stations, some closed doors and a significant part of that do so with great difficulties. In this article we analyze, starting from several indicators, the situation of local radio in Portugal at the beginning of XXI century.

Keywords: Local radio; Journalism; Portugal. 


\section{Introdução}

Portugal não ficou imune ao fenômeno de criação das rádios-pirata que invadiu a Europa a partir, sobretudo, da década de 1970. Embora ligeiramente mais tarde, o surgimento das rádios-pirata, movimento que daria origem às rádios locais, contribuiu para diversificar e alterar profundamente o cenário das mídias em Portugal e representa uma das expressões práticas do retorno da democracia e liberdade de expressão ao país. As rádios locais portuguesas carregam um lado simbólico que aponta para o pluralismo e diversidade, quer seja na informação ou na programação que veiculam. Esse aspecto é particularmente importante num país cujo espaço midiático continuava, e de certa forma ainda continua, muito centralizado nos grandes centros urbanos e em particular nas principais cidades.

O jornalismo local que é praticado nas rádios locais portuguesas é, sob este ponto de vista, de singular relevância por se apresentar como um palco para os discursos e narrativas que normalmente não se encontram nas mídias de cobertura nacional. A preservação desse palco midiático depende de políticas públicas que em conjugação com as regras do mercado deverão constituir-se como alavancas para o desenvolvimento das rádios locais, bem como a manutenção dos seus princípios originais. Contudo, há alguns sinais preocupantes que sublinham uma crise que pode colocar em causa a própria existência das rádios locais, já que muitas acabam por abandonar os princípios segundo os quais foram criadas.

A especialização territorial da informação jornalística e a expressão da comunidade de inserção acabam por ceder perante imperativos de ordem econômica e ajudados por políticas públicas comprometedoras. Em Portugal, tem-se assistido a um conjunto de alterações da programação das rádios locais que se transformam em meras emissoras musicais, afastando-se do local e da sua função social.

No presente capítulo pretende-se contribuir para uma reflexão em torno do papel do jornalismo nas rádios locais, partindo do pressuposto de que a sua prática assenta numa lógica de especialização do território e é geradora de um sentimento de partilha e solidificação da identidade das comunidades onde se inserem. Pretende-se equacionar este objetivo ontológico da radiodifusão local portuguesa com um conjunto de fatores que têm emergido no cenário português e que, ao nosso ver, comprometem a prossecução de alguns destes objetivos.

\section{A rádio, o local e a identidade}

Para o sociólogo Manuel Castells, as comunidades locais são espaços importantes para a construção de interpretações alternativas na medida em que as identidades que ali se geram entram em intersecção com outras fontes de significado e reconhecimento social. O local é visto como o ambiente no qual as pessoas se socializam e interagem criando laços e redes sociais entre os vizinhos.

Houve a produção de significado e identidade: a minha vizinhança, a minha comunidade, a minha cidade, a minha escola, a minha árvore, o meu rio, a minha praia, a minha capela, a minha paz, o meu ambiente. (CASTELLS, 2003, p.74)

A partilha e a identificação de assuntos comuns entre os seus membros têm no espaço local uma dimensão que não deverá ser minimizada, em particular num contexto de uma cultura global. É neste aspecto que Castells vê certo paradoxo por via da criação de forças políticas com bases cada vez mais locais num mundo estruturado por processos cada vez mais globais. O local é, assim, gerador de uma identidade que nasce a partir da partilha de interesses comuns e de uma maneira própria de relacionamento (GARCIA, 2012). 
As mídias em geral, e a rádio em particular, têm aqui um papel importante na construção e solidificação de uma memória coletiva e de criação de um palco para a expressão dessa identidade local, vincando as suas especificidades e características. O local significa, antes, uma nova forma de entender o mundo (DOMINGUEZ, 1997). Cádima (1999) alerta para a importância das culturas locais receberem de fora novos aspectos da cultura universal para assim serem "capazes de compreender a sua própria identidade, enfim, a especificidade que Ihes dá a sua diferença" (p. 17).

A ligação das rádios locais ao território é, sob este ponto de vista, fundamental, tendo sido, aliás, um dos principais argumentos enquanto fator distintivo da sua especificidade. As rádios locais representam, por essa via, a identidade a partir da delimitação do território. As ideias de comunhão e de partilha do mesmo espaço físico são aqui relevantes enquanto estratégia de afirmação e até mesmo comercial das empresas de radiodifusão local. Essa vertente da rádio que privilegia o local como estratégia de afirmação e identidade é seguida por outros autores. Roncagliolo (1993 apud ESCUDERO, 1998) vê a comunicação de proximidade que as rádios locais suportam como algo que muda, transforma e altera a ordem das coisas existentes. Trata-se de um tipo de comunicação identificado com o outro, realizada na horizontal e não na vertical.

Um estudo do The Office of Communications (Ofcom - entidade reguladora independente e autoridade responsável pela concorrência das indústrias de comunicação do Reino Unido) sobre o que designam de "rádios de pequena escala" (small-scale radio) compara a relação que os indivíduos têm com as rádios locais e as comunitárias. Uma das conclusões do estudo enfatiza, de forma evidente, a relação de proximidade e de identidade que os ouvintes têm para com a sua rádio local. "Não é tanto o que as rádios transmitem, mas o que representam para a sua comunidade que as torna tão especiais para os ouvintes" (OFFICE OF COMMUNICATIONS, 2011, p. 22). O mesmo estudo compara a opinião dos ouvintes sobre a rádio local e a rádio de emissão nacional. Os ouvintes referem que sentem pela sua rádio local um afeto que não é mencionado quando são questionados sobre o que sentem em relação a outras rádios. Esse afeto não decorre necessariamente da escuta permanente, mas sim do sentimento de pertença que a radio local lhes proporciona.

As rádios locais criaram condições para o renascimento de uma identidade regional, visível através do sentimento de pertença que os ouvintes nutrem pelas emissoras da sua localidade, realidade que é sobretudo observada em áreas onde as emissoras nacionais não têm uma forte implementação. Seguindo esta linha de raciocínio, as rádios locais desempenham uma função social que se sintetiza por favorecer uma renovação da vida e das iniciativas locais. A rádio local permite à comunidade conhecer-se melhor.

\section{A rádio local no contexto das mídias}

Das diversas contribuições teóricas sobre as rádios locais na Europa, subtraímos três dimensões que consideramos mais relevantes. A dimensão democrática, na medida em que as rádios locais passaram a permitir o acesso mais plural e diversificado aos meios de comunicação social (ECO, 1981); a dimensão alternativa, pois ajudaram a criar um discurso e uma racionalidade distinta dos grandes meios de comunicação centralizados no Estado e nas grandes organizações privadas (FLICHY, 1981; ESTEVES, 1988) e uma dimensão de proximidade ao gerarem condições para que a comunidade se revisse nas rádios locais e para que estas procurassem naquelas a razão da sua existência (NOSTY, 1997; ESCUDERO, 1998; STARKEY, 2011).

Há, por esta ordem de razões, uma linha que tem sido seguida e que numa perspetiva diacrônica coloca o movimento das rádios locais num patamar de 
certa afirmação das populações pela sua identidade e sobretudo da "consciência de que novos sectores da população adquiriram a possibilidade de dar a conhecer as suas opiniões e pontos de vista" (ECO, 1981, p. 229). Sob este ponto de vista, as rádios locais inscrevem-se num registo da consolidação democrática dos países onde surgiram, sobretudo porque o carácter voluntário e espontâneo do movimento das rádios locais na Europa aponta para o desejo das populações "em se incorporarem de maneira ativa na construção democrática" (ESCUDERO, 1998, p. 23-25).

É, aliás, esse o caso de Portugal ou da Espanha, onde as rádios locais adquiriram expressão justamente após o fim das ditaduras que vigoraram naqueles países. Por isso, este fenômeno de surgimento das rádios locais não poderá ser dissociado das transformações políticas, sociais e culturais do pós-guerra no continente Europeu bem como da contestação popular ao monopólio dos Estados no setor das mídias (STARKEY, 2011; FLICHY, 1981).

Quando falamos em rádios locais, falamos na verdade de um movimento (ou melhor, de movimentos, já que tomou diversas formas em função das especificidades de cada país) libertador e que pretendeu colocar no espaço público midiático correntes sociais, culturais e políticas, até então com pouca ou nenhuma expressão pública.

A ideia em torno da construção de uma racionalidade alternativa "aos grandes sistemas (nacionais e internacionais) de informação e comunicação social" (ESTEVES, 1988, p. 56) atribuída a estas rádios funda-se justamente na circunstância de se terem afirmado como um palco para a expressão de correntes culturais, sociais e até políticas, com pouco ou nenhum espaço nas mídias nacionais e pertencentes aos Estados. A especificidade da rádio tem aqui um papel importante, pois rádios comunitárias e de bairro, piratas, livres e várias formas de rádio clandestina, são fenômenos que raramente encontram paralelo numa ecologia global da televisão (CRISELL, 1994; HENDY, 2000).

Por outro lado, é o seu carácter localista que ajuda a construir essa mesma ideia de democracia e de racionalidade alternativa. Esse cenário ganha particular relevância em países em que o centralismo das mídias é mais vincado, como no caso português. As rádios locais constituíram-se como excelentes espaços para a expressão da vivência das comunidades e das populações, uma vez que, tal como refere Bernardo Diaz Nosty,

[...] no local é muito difícil criar cenários que difiram da nossa realidade, porque, nesses planos formativos tão necessários para os meios locais, não convém desprender-se em excesso da realidade em volta e atender ao direito da informação dos cidadãos. (1997, p.168)

O surgimento das rádios locais na Europa deveu-se à vontade popular que sentiu a necessidade de se expressar na cena midiática, significando, de certa forma, a expressão prática de uma nova cultura de comunicação e informação (GALINDO, 1998), consubstanciada no direito dos cidadãos a terem não só acesso às mídias enquanto receptores, mas também enquanto participantes ativos no discurso midiático.

As rádios locais contribuíram para que a própria rádio se tivesse reinventado enquanto meio de comunicação, reforçando o seu papel e condição de veículo da expressão política, social e cultural. Não faltam exemplos do que acabamos de dizer. O chamado "movimento" na Itália, que agregou diversas rádios com o objetivo de divulgar os ideais de esquerda (RODRIGO; RUIZ-COLLANTES, 1981), ou rádios verdes na França, assim designadas por defenderem a causa ambientalista, são alguns cenários enunciados. 


\section{O jornalismo como território de afirmação}

O jornalismo praticado nos meios de comunicação social local funciona como promotor de uma discursividade alternativa que se materializa numa forma própria de olhar o mundo. Os órgãos de comunicação social local e regional constituemse como uma modalidade bastante interessante de preservação e promoção dos valores e da memória coletiva da comunidade na qual se inserem. A proximidade entre os produtores das notícias e os seus destinatários poderá significar uma forma eficaz de contextualização dos acontecimentos e de compreensão dos mesmos, e nessa medida o jornalismo local contribui para uma consciência coletiva de um espaço público comum e é um veículo transmissor dos valores da cidadania, constituindo-se como "um elemento estruturador desse espaço público regional entendido como esfera crítica de debate e de interação dos cidadãos em torno dos problemas que lhe são próximos" (CORREIA, 1998, p. 156).

O jornalismo nas rádios locais aparece como um elemento definidor e que contribui para a distinção diante dos meios de comunicação social de âmbito nacional. O jornalismo local, e em particular a rádio local, é, como referem Chantler e Harris (1997), um modo de afirmação também no campo de um mercado competitivo e "uma das poucas coisas que faz o som da rádio local distinto" (p. 5).

Para Moreno (2002), o jornalismo praticado nas rádios locais tem algumas características que o distinguem de outras mídias. Sublinha a autora espanhola que se trata de um constante apelo à identidade da comunidade a que se dirige e que contribui para reforçar a identidade cultural e a presença social da emissora entre a audiência. Para a autora, a programação informativa numa rádio local tem as seguintes características: proximidade e serviço; natureza da emissora e identidade; acompanhamento da atualidade diária; reforço do caráter local da comunidade a que se dirige; proximidade com a audiência. Refere Moreno (2002):

A programação informativa local pode definir-se como o conjunto ou a parte da comunidade informativa de uma emissora que relata ao ouvinte a realidade do contexto mais próximo: a informação de atualidade geral, a informação serviço e a atualidade desportiva da localidade e da região. (p. 329)

As rádios locais inscrevem-se, assim, num registo de proximidade e especialização, valores que podem ser potenciados nas diversas dimensões de uma organização radiofônica local, como a microinformação local, a identidade local e o entretenimento (OFFICE OF COMUNICATIONS, 2011). Significa dizer que as decisões editoriais que os jornalistas tomam na sua atividade decorrem de cenários interpretativos que se baseiam num "significativo grau de conhecimento do local” (KIRBY, 1989 apud HOOD, 2010, p. 153). Em torno dessa questão gravitam fatores relacionados ao pluralismo, diversidade temática e de fontes informativas locais, que sendo especializadas ajudam na contextualização das matérias abordadas.

A defesa em torno de um jornalismo de proximidade que implique a sua especialização territorial é feita também por Nosty (1997) ao referir que as mídias locais e regionais são meios especializados geograficamente. Isso quer dizer que devem apostar em estratégias que reforcem essa especificidade. Só assim poderão criar espaços e discursos direcionados para a sua audiência específica. $O$ autor entende que 0 progresso tecnológico aplicado ao campo das mídias deve ser aproveitado por estes para se aproximarem cada vez mais das suas comunidades locais, e não o contrário. A construção e preservação de uma memória coletiva específica de uma região ou localidade depende da exata adequação de estratégias de programação que se identifiquem com essa mesma audiência. Os meios locais devem procurar adequarse à região de cobertura e se o não fizerem estão "a afastar-se dos seus objetivos e cavando o buraco da sua autodestruição" (NOSTY, 1997, p. 164). 
A microinformação local é vista como um serviço exclusivo das rádios de pequena dimensão, sobretudo devido ao seu grau de especialização. É o tipo de informação que as rádios de maior dimensão ignoram e por essa razão constituise como um importante elemento de atração de ouvintes para as rádios locais (OFFICE OF COMMUNICATIONS, 2010). O grau de especialização e adequação à comunidade onde se insere é visto por Moreno (2002) como essencial:

A rádio regional e local participa e forma parte da comunidade a que se dirige. A informação mais próxima é um conteúdo essencial deste tipo de rádio. O seu tratamento e desenvolvimento na rádio converte-a num fórum de encontro comunicativo que contribui para ampliar a identidade informativa e cultural do ouvinte local. (p. 349)

Faz todo o sentido que o território local signifique a principal área de intervenção dos jornalistas das rádios locais, como forma, por um lado, de sublinhar a sua diferença, e por outro para contextualizar, tendo em conta o seu público, os acontecimentos que chegam "de fora". É nesse sentido que devemos falar em especialização territorial do jornalismo local.

\section{Anatomia das rádios locais em Portugal}

Até a legalização das rádios locais em Portugal, ocorrida com a lei publicada em 1988, o cenário da rádio caracterizava-se por um duopólio entre o Estado e a Igreja. O surgimento das rádios locais portuguesas é precedido de um período de onze anos durante o qual apareceram um pouco por todo o país centenas de rádios-pirata, que assim ficaram conhecidas por emitirem sem licença.

Este período pode ser dividido em duas fases. A primeira, entre 1977 e 1984, altura em que o fenômeno se caracterizou pelo aparecimento de pequenas emissoras em vãos de escada, impulsionadas pela carolice e amadorismo dos seus criadores. Mais do que criar bases sólidas para uma rádio, pretendiam despertar a opinião pública para um movimento que despontava um pouco por toda a Europa.

Numa segunda fase, entre 1985 e 1988, surgiram vários projetos com alguma dimensão e que visavam já não apenas a afirmação de uma ideia, mas a legalização da radiodifusão local em Portugal.

Em países como Itália, França ou Espanha, as movimentações no sentido de legalizar as rádios livres tinham já repercussões e esses ecos chegavam a Portugal contribuindo para exercer maior pressão junto do poder político no sentido de encetar medidas efetivas para legalizar a radiodifusão local portuguesa. $O$ contexto pós-revolucionário vivido no Portugal de então também não é alheio a todo este processo. A primeira rádio-pirata terá aparecido três anos após a Revolução de 1974 e as próprias designações das rádios não escondem o pendor irreverente de que o fenômeno se revestiu. Rádio Delírio, Rádio Caos, Rádio Livre ou Rádio Porta Aberta são apenas alguns exemplos.

As primeiras emissões das rádios piratas caracterizaram-se, sobretudo, pela intenção de ir contra as convenções dominantes. Não se pretendia dar voz a grupos sociais oprimidos, como se verificou em muitos países da Europa, mas a populações locais que normalmente não apareciam nos noticiários das rádios nacionais. O carácter experimentalista da maior parte das rádios-piratas, bem como o amadorismo dos seus impulsionadores, caracterizaram o fenômeno nos primeiros anos de existência.

A rapidez com que no terreno se multiplicava o número de novas rádios-pirata, a criação de um conjunto de acordos internacionais que transformaram o cenário 
da radiodifusão europeia e por fim a alteração da conjuntura nacional no que respeita à liberdade de expressão conduziram à necessidade, cada vez mais evidente, de atualizar o quadro legal para a atividade da radiodifusão em Portugal, que ainda era regulado, a meio da década de 1970, por um diploma de 1933.

O ano de 1988 assinala, pois, um importante momento na radiodifusão portuguesa com a publicação da lei $87 / 88$ de 30 de Julho, que legaliza as rádios locais em Portugal, culminando um complexo processo iniciado em 1977, quando se estima ter aparecido a Rádio Juventude, a primeira rádio-pirata no país (MAIA, 1995). A maior parte das rádios locais foram criadas por iniciativa individual, ou por pequenos grupos de pessoas normalmente ligadas à eletrotecnia que, dotados de conhecimentos ao nível técnico, Ihes permitia montar e retirar com facilidade as antenas e assim escapar à fiscalização.

Porém, ultrapassado o período da euforia que varreu o país de norte a sul e que acabou com a desejada legalização das emissoras piratas, teve início um processo complicado de gestão desses mesmos projetos. A distribuição de frequências criou, por si mesma, uma clara divisão entre o litoral e o interior do país que foi agravada nos primeiros três a quatro anos com o encerramento de algumas rádios locais no interior de Portugal. Este fato criou um cenário perverso, uma vez que era precisamente no interior do país (onde as alternativas ao nível da comunicação social eram menores) que se fazia sentir com mais intensidade a necessidade de rádios que estivessem próximas das populações. Mas os primeiros cinco anos (nalguns casos nem foi preciso esperar tanto tempo) puseram a nu as debilidades financeiras e estruturais da maior parte das estações locais de rádio.

Mesquita (1994) sintetiza assim o período imediato à legalização das rádios piratas:

De 1990 a 1993 são numerosas as alterações deste sector. Estações que fecham, que se associam a outras, que são vendidas, que alteram radicalmente o seu projecto inicial, enfim, a rádio local está longe de encontrar o seu ponto de estabilidade. (p. 400)

É nesse contexto que podemos identificar três situações distintas entre 1989 e 1994. A primeira na qual as rádios locais, apesar de terem obtido licença para emitir, não o faziam por falta de recursos, uma situação que ocorreu particularmente no interior do país. O segundo cenário caracterizou-se pela venda de espaços horários ou mesmo da totalidade da sua programação a confissões religiosas que, em poucos anos, conseguiram deter um número significativo de emissoras de norte a sul de Portugal. Por fim, assistiu-se a um processo de canibalização com a constituição de cadeias de rádios, nas quais as emissoras com maiores recursos, numa tentativa de cobrir todo o território, firmaram protocolos com rádios locais para a retransmissão da sua programação. Essa estratégia revelou-se também benéfica para as emissoras locais com menores recursos, pois parte da sua grelha de programação passou a estar preenchida, algo que de outro modo não aconteceria por falta de meios. Mas se por essa via os efeitos foram positivos, por outro lado contribuiu para afastar as rádios locais das comunidades onde se inseriam.

\section{Um contexto difícil para a sobrevivência do local}

O contexto para o desenvolvimento das empresas de comunicação social local em Portugal não tem sido muito favorável. As razões para uma persistente crise têm sido apontadas e decorrem de fatores culturais, sociais e sobretudo econômicos, num país com o seu perfil geográfico próprio no qual são evidentes as assimetrias litoral/interior e consequentemente os diferentes níveis de aceleração e desenvolvimento econômico das regiões. As organizações de comunicação social em Portugal operam num contexto altamente segmentado 
e como tal não suportam muitas empresas a atuar nesses mercados (FAUSTINO, 2000). As rádios locais são disso um claro exemplo, pois em vários concelhos do país foram inicialmente aprovados projetos para funcionarem duas ou três emissoras que têm que disputar o mesmo exíguo mercado publicitário. $O$ cenário que daí resulta é o encerramento de algumas, a venda a outras de maior dimensão ou simplesmente a mudança para formatos de programação menos onerosos, os musicais, descurando assim a vertente informativa local.

Por outro lado, a iliteracia, resultado do fraco investimento na formação e educação, assim como a fragilidade das mídias locais e regionais é sintoma de um país cujas empresas jornalísticas regionais estão muito aquém das suas verdadeiras potencialidades. Esta iliteracia afeta a imprensa regional e local no país (CARVALHO et al., 2010).

Esses cenários têm dificultado o desenvolvimento das empresas jornalísticas de menor dimensão localizadas em áreas economicamente mais desfavorecidas do país. De um outro modo, sublinham os autores do "Estudo de Impacto dos Incentivos diretos concebidos pelo Estado aos órgãos de comunicação social regional e local" (CARVALHO et al., 2010), a imprensa regional e a local, incluindo as rádios locais, revelam alguma dependência de subsídios do Estado, nomeadamente através do Gabinete para os Meios de Comunicação Social das autarquias, das igrejas e de entidades particulares que tiram partido das suas potencialidades enquanto órgãos de comunicação social.

A modernização dos projetos editoriais regionais e locais passa, necessariamente, pela salvaguarda da independência destes face aos poderes políticos, religiosos, e em especial na salvaguarda da idoneidade ao poder autárquico (CARVALHO et al., 2010). O mesmo estudo sublinha as dificuldades estruturais e organizacionais das empresas de radiodifusão local em Portugal ao notar a existência de uma elevada percentagem (87\%) de micro empresas, ou seja, empresas cujo volume de negócios não excede os dois milhões de euros e o número de trabalhadores é inferior a 10 trabalhadores assalariados. Verifica-se, igualmente, uma percentagem baixa (13\%) de pequenas empresas, cujo volume de negócios é inferior ou igual a 10 milhões de euros e o número de trabalhadores assalariados é inferior a 50.

Também a Associação de Rádios de Inspiração Cristã (ARIC), que representa várias rádios locais portuguesas, traça em 2013 um cenário preocupante. De acordo com o Estudo sobre os Principais Grupos de Custos de Financiamento das Rádios Associadas da ARIC, $80 \%$ das emissoras "assinalam quebra no desempenho económico e as rádios estão a diminuir custos em áreas chave da Organização como por exemplo os Recursos Humanos" (ASSOCIAÇÃO DE RÁDIO DE INSPIRAÇÃO CRISTÃ, 2013, s. p.). O estudo evidencia ainda que entre 2012 e 2013 aumentou o número de rádios locais que registaram nesse período quebra de atividade econômica. Esse cenário teve reflexos a vários níveis, em particular nos recursos humanos das estações de rádio, como assinala o estudo. "Em termos de quantificação de efetivos se em 2012, já se perspetivavam valores para reduções de colaboradores, na ordem dos 24 trabalhadores, agora esse valor ascende a 45 pessoas, ou seja, quase duplica" (ASSOCIAÇÃO DE RÁDIO DE INSPIRAÇÃO CRISTÃ, 2013, s. p.).

Um olhar mais atento para os projetos jornalísticos existentes nas rádios locais em Portugal, permite-nos identificar as consequências de algumas destas debilidades acima referidas. Nas rádios locais que proliferam pelo país, persiste, ainda hoje, um cenário composto por redações com escassos recursos humanos e técnicos, o que condiciona a informação difundida. Em 2003, e com base num estudo de quatro rádios locais da Península de Setúbal, ao sul de Lisboa, verificou-se que essas redações eram compostas por 1 a 4 jornalistas (BONIXE, 2003), cenário que se mantém quase uma década depois a avaliar pelos dados recolhidos no estudo já referido sobre o impacto dos incentivos do estado aos 
meios de comunicação social local. Nesse estudo é referido que a maior parte das rádios locais portuguesas analisadas

[...] possuem poucos funcionários ao serviço, circunstância que reflete a sua vulnerabilidade. É na categoria de 1 a 3 funcionários e na categoria de 4 a 6 funcionários que se enquadram a maioria das empresas, para qualquer um dos anos em estudo. (CARVALHO et al., 2010, p. 122)

Outro estudo realizado por meio de inquérito a uma amostra de 28 jornalistas de rádios locais em Portugal (BONIXE, 2013) vem sublinhar as dificuldades com que os jornalistas que exercem a sua atividade nas rádios locais se debatem ao revelar que estes profissionais exercem a sua profissão em redações de pequena dimensão em que o número de jornalistas oscila entre apenas 1 e 4 . Por outro lado, apesar da maioria dos inquiridos ser detentor de um curso superior, a maior parte dos respondentes não aufere um vencimento superior a 650 euros mensais, ou seja, um pouco acima do ordenado mínimo nacional. De acordo com o mesmo inquérito, os jornalistas que nele participaram revelaram que a sua maior preocupação no que diz respeito à política editorial da sua rádio é justamente o pouco trabalho de reportagem que efetuam, situação que se deve, em boa parte, à falta de mais profissionais nas redações.

Para contornar esses problemas e manter viva a sua função social de informação local, algumas rádios locais encetaram no passado algumas experiências no sentido de rentabilizar os recursos humanos existentes. É disso exemplo a Cadeia de Informação Regional criada em 1997 e que agregava oito rádios dos distritos de Bragança e Vila Real, no interior de Portugal. Em 1999, as rádios Clube de Sintra e de Cascais seguiram o mesmo exemplo. Pretendiam essas emissoras criar uma cadeia metropolitana de Rádios em Lisboa segundo a qual, duas vezes por dia, uma das duas rádios emitiria um noticiário alargado em coprodução pelas duas estações. Desta forma chegariam a um auditório mais vasto, e as receitas da publicidade que ia para o ar, antes e depois do noticiário, revertiam a favor de ambas as rádios. De forma esporádica, algumas rádios locais do Baixo Alentejo (Rádio Sines, Miróbriga, de Santiago do Cacém, são alguns exemplos) colaboraram entre si permitindo uma maior cobertura noticiosa dos eventos que ali ocorrem. Mas esta prática de juntar sinergias de modo a rentabilizar os reduzidos recursos humanos nas redações tem sido pouco comum, como nota Santos (2008): "poucas rádios formam associações e tentam fundir projetos, preferindo políticas de rivalidades locais" (p. 89).

\section{Jornalismo, localismo e consolidação econômica}

Temos visto ao longo deste capítulo como o fenômeno das rádios locais alterou radicalmente o cenário das mídias em Portugal. Contribuiu, em muitos casos, para a afirmação de uma identidade local, gerando espaços de debate e discussão sobre temáticas públicas. As emissoras locais contribuíram para a memória coletiva de uma comunidade e para o pluralismo informativo. Não menos importante foi o contributo que deram para o acesso à profissão de jornalista em Portugal, como é notado no estudo sobre isso: "O número de profissionais de rádio duplicou de 1988 a 1989 [...] recorde-se que o período de 1987 a 1991 corresponde à fase de legalização das anteriormente denominadas rádios-pirata" (REBELO, 2011, p. 69-70).

Porém, neste início da segunda década do século XXI, no caso português, há indicadores que mostram alguns sinais de preocupação com o futuro do jornalismo que é praticado nas rádios locais. Assistimos atualmente a um cenário motivado por políticas e estratégias empresariais que aliadas ao plano legislativo estão a contribuir para que as rádios locais se afastem dos seus objetivos de promoção e criação de espaços de discurso e memória coletiva das comunidades onde se inserem. Um desses indicadores é o número de rádios locais que, aproveitando 
a legislação favorável, têm solicitado às entidades competentes a alteração dos seus projetos de generalistas para temáticas. Segundo dados do Gabinete para os Meios de Comunicação Social, até 2006 encontravam-se licenciadas 22 rádios temáticas, sendo que destas 18 foram classificadas como musicais e apenas quatro informativas.

Ou seja, as rádios locais, motivadas por questões de natureza diversa como dificuldades econômicas ou recrutamento de jornalistas, estão a abdicar da sua vertente informativa, desligando-se, deste modo, das comunidades onde se inserem, pois a alteração para rádio temática musical não obriga a transmissão de informação jornalística. No relatório de 2010 da Entidade Reguladora da Comunicação (ERC), essa preocupação era manifestada em relação aos pedidos de alteração da programação feitos pelas emissoras.

Assistiu-se, em 2010, a uma tendência, que começa a sedimentar-se no panorama radiofónico nacional, entre as rádios de âmbito local, no sentido da alteração dos respetivos projetos radiofónicos visando a sua adaptação a modelos pré-existentes, já reconhecidos ou reconhecíveis pela audiência, disso sendo reflexo os pedidos de alteração do projeto aprovados (15), assim como de alteração da denominação dos serviços (18). (ENTIDADE REGULADORA DA COMUNICAÇÃO, 2012, p. 23)

O número de pedidos de alteração de programação conheceu um novo impulso aproveitando a entrada em vigor em 2010 de nova legislação para o setor. Assim, em junho de 2012, menos de dois anos após a aprovação da nova lei, a imprensa da altura noticiava que a Entidade Reguladora para Comunicação já tinha aprovado 10 pedidos de alteração de programação e que se preparava para "analisar mais outros cinco processos de alteração" (MEIOS \& PUBLICIDADE, 2012, s. p.)

Esses dados geraram preocupação mesmo no seio da entidade reguladora. De fato, a própria ERC, na sequência dos pedidos de alteração de programação, viuse na obrigação de emitir em 2012 uma recomendação sobre a promoção da diversidade informativa nas rádios na qual manifestava a sua preocupação quanto à manutenção do pluralismo informativo nas rádios locais portuguesas.

Na diretiva emitida pela Entidade Reguladora da Comunicação (2012) pode ler-se o seguinte:

Lei n.o 54/2010 (doravante, Lei da Rádio) eliminou as restrições anteriormente consagradas à possibilidade de alteração da tipologia das rádios locais, em função da existência ou não, no mesmo concelho, de rádio generalistas, daí que se venha assistindo a uma tendência de modificação da tipologia dos serviços de programas de generalistas para temáticos musicais, com o consequente desaparecimento das rádios generalistas [Neste sentido, a ERC recomendou na diretiva que seja salvaguardada] [...] uma componente informativa de caráter local (s. p.)

Mesmo em termos internacionais, a preocupação em manter local a rádio local é evidente. Por exemplo, em 2004 o relatório anual do Project for Excelence in Journalism referia que no caso norte-americano os dados disponíveis apontavam para um número cada vez maior de rádios locais que estavam, na prática, a deixar de o ser, apesar do "desejo das audiências por informação local" (PROJECT FOR EXCELLENCE IN JOURNALISM, 2004).

A entrada de grupos de comunicação no setor das rádios locais portuguesas é motivo que merece, igualmente, análise. Neste particular, há duas dimensões do fenômeno que importa referir. Em primeiro lugar, a entrada de grupos econômicos sólidos tem ajudado a sobrevivência de várias rádios locais portuguesas na medida 
em que contribui, por exemplo, para a captação de investimento publicitário. Mas, por outro lado, a concentração de rádios no seio do mesmo grupo econômico tem levado a comprometer o localismo próprio dessas emissoras naquilo que é considerado como uma perversão (CÁDIMA, 1999). Para Tristani (1998), a concentração de rádios locais no mesmo grupo econômico põe em risco a cobertura de temáticas locais, reportagem, programação local e a capacidade para servir de espaço para as vozes locais. Também para Starkey (2011), a entrada em cena de grupos de comunicação nacionais ou até internacionais ao adquirirem emissoras locais tem conduzido a um cenário de "diminuição do sentido de localidade", uma vez que

[...] colocam em situação desvantajosa as comunidades das quais procuram obter lucro [...] A diminuição do sentido de localidade está a ocorrer de várias maneiras, mas na sua essência pode ser racionalizada no facto de estações de rádio comerciais de propriedade local [...] estarem a cair no controlo de grupos nacionais e até de grupos internacionais de média, que colocam em situação desvantajosa as comunidades das quais procuram obter lucro $(2011$, p. 158)

Em Portugal, a dimensão dessa questão não é uniforme. Se nas regiões em torno das zonas metropolitanas de Lisboa e do Porto o cenário é já de várias emissoras locais que estão sob propriedade de grupos econômicos, no interior do país o fenômeno parece ainda não ter ganhado uma dimensão muito significativa, apesar de em 2013 o principal grupo de rádios a operar em Portugal, a Média Capital, ter adquirido nove frequências locais em várias localidades do país com o objetivo de retransmitir as rádios dedicadas a programação musical como a Star FM ou a M80. Nesses casos, essas localidades ficaram claramente a perder no que diz respeito à informação local.

A concentração de rádios locais no mesmo grupo econômico conduz inevitavelmente à concentração dos próprios serviços, o que pode, igualmente, levar a estratégias que promovam o afastamento do local. Hood, olhando para o cenário norte-americano, nota como sendo negativa a estratégia que as rádios locais têm seguido de outsourcing, ou seja uma prática que significa que os noticiários de uma rádio local são emitidos a partir da "rádio mãe", mesmo que esta esteja a vários quilômetros de distância. O problema dessa prática, sublinha Hood, é que as notícias são na maior parte dos casos destituídas do seu carácter de proximidade e territorialização. O resultado, refere o autor, será um afastamento da especificidade dessa informação e como tal da ligação aos assuntos de uma cidade (HOOD, 2010).

\section{Notas finais}

As rádios piratas portuguesas, sobretudo pela sua expressão quantitativa, modificaram o jornalismo radiofônico português. Contribuíram, pelo menos no início, para o exercício de um jornalismo de proximidade, trazendo para o cenário radiofônico um olhar sobre os pequenos problemas locais das populações, bem como novos protagonistas que eram frequentemente esquecidos pelas principais rádios de cobertura nacional. Foi este movimento que permitiu o aparecimento de emissoras que acabariam por se destacar no campo informativo, entre as quais o exemplo mais relevante é a TSF, uma das principais rádios portuguesas de informação.

As rádios locais afirmaram-se como verdadeiras escolas práticas de jornalismo radiofônico espalhadas por todo o país. Foi nas rádios locais que nasceram para a profissão vários jornalistas que mais tarde integrariam as principais redações nacionais, não apenas da rádio, mas também da televisão e da imprensa.

Olhando em particular para o caso português, que aqui procuramos analisar à luz dos fundamentos e princípios da radiodifusão local, o jornalismo e a 
procura por uma informação com origem no território, e como tal específica e distintiva da restante informação, sempre se constituiu como um argumento para a sua própria existência. Nesse sentido, as rádios locais surgem no contexto português com uma relevância que lhes é atribuída enquanto geradoras de um discurso coletivo que promove o local e contribui para a preservação de uma memória coletiva.

As rádios locais têm condições ontológicas favoráveis para a prossecução de tais objetivos. À partida, porque estamos a falar de rádio e, como tal, de um meio que promove, pelas suas caraterísticas, uma ligação de proximidade com os ouvintes, seja através da sua própria linguagem, seja pela facilidade tecnológica que Ihe confere portabilidade. Por outro lado, a dimensão local dessas rádios é o sentido da sua existência. No entanto, tal como procuramos demonstrar, há fatores que perturbam aquilo que seria o percurso normal de uma rádio local. Encontramos esses indicadores no plano legislativo com a aprovação de leis que geram condições favoráveis para o afastamento do local criando condições para que no plano empresarial sejam adotadas estratégias que não têm o local como prioridade.

Naturalmente que os planos financeiro (falamos na sua maioria de empresas com dificuldades econômicas) e organizacional (tratam-se em muitos casos de rádios com pequenas estruturas ao nível de recursos humanos e materiais) não devem ser esquecidos. Nesse aspecto, tentou-se criar um plano de incentivos que ajudasse a modernização tecnológica, mas um estudo sobre a eficácia desses apoios mostra como eles não tiveram o resultado desejado. "O impacto desses apoios está longe de ter alcançado os objectivos, uma vez que não foram suficientes para potenciar uma maior dinâmica geral deste subsector" (CARVALHO, et al., 2010, p. 287).

Por razões históricas e ontológicas, não é possível dissociar rádio local de proximidade, e é nesse quadro que as políticas públicas para o setor da rádio devem ser adotadas, considerando, por outro lado, os desafios que o século XXI coloca aos meios de comunicação social em geral e à rádio em particular. A linha que seguimos no presente texto afirma a rádio local enquanto espaço simbólico para a troca simbólica entre os indivíduos de uma comunidade e enfatiza a especificidade do local traduzida em termos jornalísticos numa especialização territorial dos conteúdos. É, por isso, necessário fortalecer as rádios locais neste domínio criando condições para que os profissionais, sobretudo os jornalistas, possam exercer a sua função com base na experiência direta do território, condição, nesse contexto, fundamental para o conhecimento.

\section{Referências Bibliográficas}

ASSOCIAÇÃO DE RÁDIO DE INSPIRAÇÃO CRISTÃ. Estudo sobre os principais grupos de custos de financiamento das rádios associadas da ARIC. 15 abr. 2013. Disponível em: <http://www.aric.pt/noticia.php?id=1002>. Acesso em: 16 abr. 2013.

BONIXE, L. As rádios locais em Portugal: informação e função social. Uma análise dos noticiários das rádios do distrito de Setúbal. 177 f. Dissertação (Mestrado em Ciências da Comunicação) - Universidade Nova de Lisboa, Lisboa, 2003.

BONIXE, L. Legalização, concentração e multimédia - os desafios das rádios locais portuguesas. Rádio-Leituras, ano 1, jul./dez., 2010. p. 187-202.

BONIXE, L. Jornalismo e jornalistas das rádios locais portuguesas. [Seminário "25 Anos de Rádios Locais em Portugal" para Escola Superior de Educação de Portalegre], Escola Superior de Educação de Portalegre, 18 abr. 2013.

CÁDIMA, F. R. Desafios dos novos media. Lisboa: Editorial Notícias, 1999. 
CARVALHO, A. et al. Estudo de impacto dos incentivos diretos concebidos pelo Estado aos órgãos de comunicação social regional e local. Lisboa: UNL-Média XXI, 2010.

CASTELLS, M. O poder da identidade. Lisboa: Calouste Gulbenkian, 2003.

CHANTLER, P.; HARRIS, S. Local Radio Journalism. Oxford: Focal Press, 1997.

CORREIA, J. C. Jornalismo e espaço público. Covilhã: Universidade da Beira Interior, 1998.

CRISELL, A. Understanding radio. London: Routledge, 1994.

DOMINGUEZ, J. M. Los media locales en la Cataluña y la ACL. In: ESCUDERO, M. C. (Org.). Radiotelevisión pública local y alternativa - perspectivas. Sevilla: EMA RTV, 1997. p. 217-224.

ECO, U. Una nueva era en la liberdad de expresión. In: BASSETS, L. (Org.). De las ondas rojas a las radios libres. Barcelona: Gustavo Gili, 1981. p. 213-230.

ENTIDADE REGULADORA PARA A COMUNICAÇÃO SOCIAL. Diretiva sobre a promoção da diversidade informativa nas rádios Deliberação. [Online], 10 jul. 2012. Disponível em <http://www.erc.pt/download/YToyOntzOjg6lmZpY2hlaXJvljtzOjM5OiJtZWRpYS9kZWNpc29lcy9vYmplY3RvX29mZmxpbmUvMTk4OC5WZGYiO3M6NjoidGIOdWxvljtzOjlyOiJkZWxpYmVyYWNhby0xb3VOLXlyMDEyljt9/deliberacao-1out-r2012>. Acesso em: 22 abr. 2009.

ESCUDERO, M. C. Radio Pública Local. Madrid: Fragua, 1998.

ESTEVES, J. P. Comunicação regional e local em Portugal. Comunicação $e$ linguagens, n.8, p. 55-70, 1998.

FAUSTINO, P. A imprensa regional em Portugal: o estado da arte e práticas de gestão. Revista Observatório, n. 1, maio, p. 89-96, 2000.

FLICHY, P. La explosión del monólogo. Las radios paralelas en la Europa Occidental. In: Basstes, L. (Org.). De las Ondas Rojas a las Rádios Livres. Barcelona: Gustavo Gili, pp.180-188, 1981.

GALINDO, J. A. G. Participación social y democracia: los ciudadanos y los medios de comunicación. In: ESCUDERO, M. C. (Org.). La democratización de los medios radiotelevisión comunitária. Sevilha: II Congreso de Radio y Televisiones Locales, Públicas y Alternativas, 1998. p. 289-295.

GARCIA, R. T. Vínculos comunicacionais e sentimento nacional: noção tradicional e Internet. In: De Oliveira Menezes, J. E. \& Cardoso, M. (Orgs.). Comunicação e Cultura do Ouvir. Editora Plêiade: São Paulo. pp. 247-265, 2012.

HENDY, D. Radio in the Global Age. Cambridge: Polity Press, 2000.

HOOD, L. Radio Recentered: Local News Returns Home. Journal of Radio \& Audio Media, vol. 17, n. 2, p. 151-166, 2010.

KIRBY, A. A sense of place. Critical Studies in Mass Communication, 6(3), 1989.

MAIA, M. A telefonia. Lisboa: Círculo dos Leitores, 1995.

MEIOS \& PUBLICIDADE. É terrível o que se está a passar com as rádios locais. 18 jun. 2012. Disponível em: <http://www.meiosepublicidade.pt/2012/06/e-terrivelo-que-se-esta-a-passar-com-as-radios-locais/>. Acessado em: 12 fev. 2013.

MESQUITA, M. (1994). Os meios de comunicação social. In: REIS, A. (Org.). 20 
anos de democracia em Portugal. Lisboa: Circulo dos Leitores. 1994. p. 360-405.

MORENO E. M. El tratamiento radiofónico de la información local. In: MARTINEZCOSTA, M. P. (Org.). Información radiofónica. Barcelona: Ariel, 2002. p. 330-349.

NOSTY, B. D. Los medios públicos regionales y locales - el futuro de los canales autonómicos y los medios locales públicos. In: ESCUDERO, M. C. (Org.). Radiotelevisión pública local y alternativa - perspectivas. Sevilla: Associación de Emissores Municipales de Andalucia de Radio y Televisón, 1997. p .157-169.

OFFICE OF COMMUNICATIONS, (2011). The future of Small Scale Radio - A Research Report of Ofcom. [Online], Julho, disponível: http://stakeholders.ofcom.org.uk/ binaries/research/radio-research/smallradio.pdf. Acessado em: 10 abr. de 2013.

PROJECT FOR EXCELLENCE IN JOURNALISM. Radio Intro. [Online], 2004, disponível: http://stateofthemedia.org/2004/radio-intro/. Acessado em: 22 abr. 2009.

REBELO, J. Ser jornalista em Portugal - perfis sociológicos. Lisboa: Gradiva, 2011.

RONCAGLIOLO, R. Editorial de la revista La triba. Buenos Aires, nov. 1993.

RODRIGO, M.; RUIZ-COLLANTES, X. Cronología. In: BASSETS, L. (Org.). De las ondas rojas a las rádios livres. Barcelona: Gustavo Gili, 1981. p. 265-276.

SANTOS, R. As rádios locais em Portugal, 2000-2004. In: PINTO, M.; MARINHO, S. (Orgs.). Os media em Portugal nos primeiros cinco anos do século XXI. Porto: Campo das Letras, 2008.

STARKEY, G. Directo e local nunca mais? As comunidades de ouvintes e as tendências de globalização na propriedade e produção de rádios locais. Comunicação e Sociedade, v. 20, p. 157-172, 2011.

TRISTANI, G. Keeping the local in local radio: remarks of FCC Commissione Gloria Tristani before the Texas Broadcasters Association. 3 set. 1998. Disponível em: <http:// transition.fcc.gov/Speeches/Tristani/spgt811.html>. Acesso em: 17 maio 2006. 